\title{
Política, poder y democracia en el proceso de producción del discurso de la entrevista política de televisión en vivo: el caso Todo se sabe
}

\section{Carmen Amalia Del Río Villanueva}

doi: 10.46476/ra.vi1.16

\section{Resumen}

¿Cómo dialogamos sobre política en el Perú? Tal inquietud inspiró una tesis cuyo estudio se enfocó en una instancia muy específica de diálogo político: la entrevista política de televisión en vivo (EPTV), producto de las "prácticas» ${ }^{2}$ del periodismo televisivo peruano. El caso Todo se sabe $e^{3}$, considerado especialmente representativo de tal fenómeno, fue objeto de análisis en sus emisiones del 04 al 08 de diciembre del 2017. A partir de él, se desentrañó el proceso de producción del discurso, con especial foco en el desempeño de la entrevistadora (Milagros Leiva), y se estudió de qué manera encarnaba los conceptos de política, poder y democracia. Para ello, se construyó un método con cuatro factores de análisis: temporal-cuantitativo, lógico-argumentativo, de pertinencia informativa, y de interacción y comunicación. Entre los hallazgos, encontramos una EPTV que difiere, sustancialmente, de la naturaleza de la práctica social conceptualizada desde diversos ámbitos del conocimiento, reconfigurándola, a la par que se divorcia de las competencias que los expertos consideran son las requeridas para el desarrollo de entrevistas eficaces que cumplan con su función social.

1. Tesis para optar el título de Magíster en Ciencia Política y Gobierno con mención en Políticas Públicas y Gestión Pública (Del Río Villanueva, 2018).

2. O proceso de producción del discurso (Fairclough, 1992).

3. Programa de RPP TV. 


\section{La investigación}

El interés por esta investigación surgió al observar que en la EPTV, diversos entrevistadores desplegaban "prácticas» que no solo parecían generalizarse, sino también intensificarse, teniendo como posible correlato su naturalización. Tales «prácticas» se manifestaban a través del uso del lenguaje. A partir de ello, nos adentramos en un ámbito casi nada estudiado en el Perú - al menos no vinculando la Ciencia Política con el Análisis Crítico del Discurso (ACD) -, que se enfoca, además, en una de las partes que suele pasar desapercibida cuando de vigilar el accionar de los actores políticos se trata, pero cuyo desempeño debe ser materia de reflexión, a saber: el entrevistador político.

En la Ciencia Política el uso del lenguaje no suele ser materia de reflexión. Por el contrario, se lo da por sentado, como si se tratara de un elemento neutral que solo sirve para «reflejar» el mundo. Sin embargo, desde otros ámbitos del conocimiento, el lenguaje es considerado como el vehículo para la acción social. Uno de esos ámbitos es el ACD, al cual se adscribe Fairclough (1992), quien concibe al discurso como lenguaje en uso, como una práctica social a través de la cual las personas no solo representan su mundo, sino que también actúan sobre él, significándolo, esto es, constituyéndolo y construyéndolo desde el significado (pp. 63-65). Este autor plantea un modelo según el cual, todo evento discursivo puede ser materia de análisis en tres niveles (pp. 71-73): texto, práctica discursiva y práctica social.

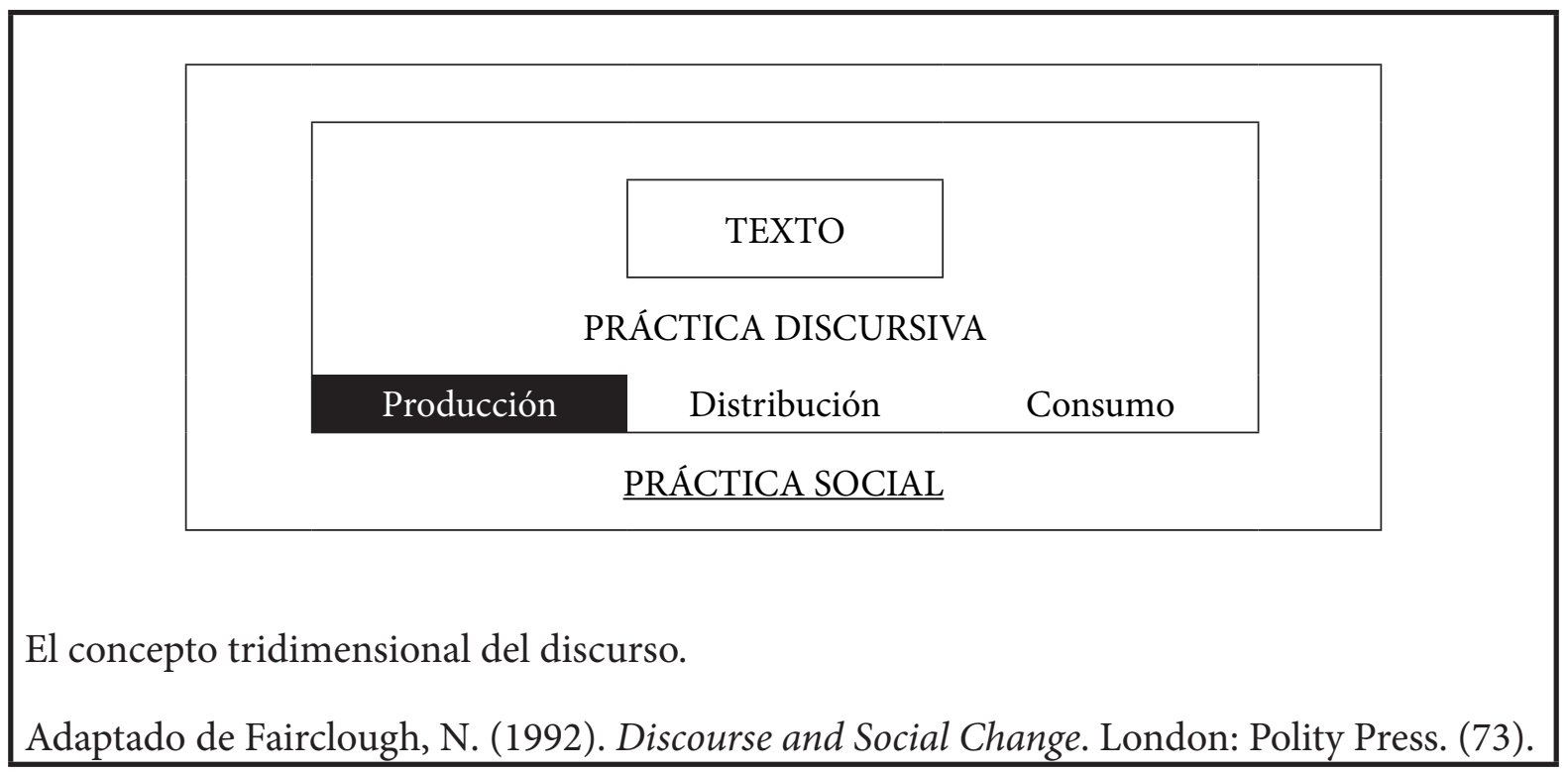

Con este marco, se estudió la EPTV a nivel de la práctica discursiva, específicamente, el proceso de producción, uno que se encuentra socialmente constreñido por: (i) la naturaleza específica de la práctica social y (ii) los recursos de las personas (Fairclough, 1992, p. 80). 
La naturaleza específica de la práctica social. Desde diversos campos del conocimiento (teoría política, periodismo, sociología) se concibe a la EPTV como una práctica social de impronta democrática ${ }^{4}$, donde el entrevistador - presuntamente guiado por los valores de neutralidad ${ }^{5}$ y objetividad ${ }^{6}$ - interroga a personas en posiciones de poder político, a fin de conocer la información que ellas tienen por ofrecer, y es dicha información la de valor noticioso. A su vez, la EPTV es un proceso emergente de producción de noticias (lo dicho allí, y cómo es dicho, configura la noticia), con un tipo de habla institucionalizada (el entrevistador es quien hace las preguntas y la persona entrevistada es quien las responde) y pública (para la audiencia, impactando así en el contenido, y "prácticas», de otras instancias de diálogo político).

En este punto, cabe precisar que, inevitablemente, ningún uso del lenguaje es neutro u objetivo. Cada vez que usamos el lenguaje lo hacemos a través de elecciones léxicas que excluyen a otras, así como lidiamos con significados que «flotan»y que se sitúan según el contexto; esto va aunado a otras consideraciones, como que no todas las personas tienen igual acceso a los medios, o que las asunciones no explícitas (con las que se abordan las entrevistas) no llegan a ser materia de discusión (sobre todo cuando provienen del entrevistador). Aun así, existe expectativa de una «neutralidad formal» del entrevistador (Clayman \& Heritage, 2004, pp. 120-126), traducida en, por ejemplo, no dar opiniones propias o no ir en pro/contra de lo manifestado por la persona entrevistada.

Los recursos de las personas. Son parámetros de referencia para el desempeño del entrevistador: (i) el sistema de toma de turnos caracterizado por el formato pregunta-respuesta según el cual, los entrevistadores se restringen a sí mismos a elaborar preguntas, «ellos no pueden - por lo menos abiertamente- expresar opiniones, o discutir con, debatir, o criticar, las posiciones de los entrevistados, ni, por el contrario, estar de acuerdo con, apoyarlas o defenderlas» (Clayman \& Heritage, 2004, p. 98), mientras que los entrevistados se restringen a sí mismos a responder a las preguntas, «ellos no pueden hacer preguntas... [o] comentarios no solicitados» (Clayman \& Heritage, 2004, p. 98); y (ii) las competencias que los entendidos sobre la materia consideran que todo entrevistador debiera desarrollar para llevar a cabo entrevistas que cumplan con su función social.

En base a estos componentes, se construyó un método de análisis de la EPTV compuesto por cuatro factores:

4. Para Dahl (1989, p. 16), la democracia se soporta en ocho garantías, entre ellas: la libertad de expresión y la diversidad de fuentes de información, así como, el debate público es uno de los dos ejes que dan cuenta del nivel de democratización de los sistemas políticos.

5. Balancear los puntos de vista.

6. Como imparcialidad y adversariedad. 
1. Temporal-cuantitativo, dedicado a la medición de los aspectos cuantitativos de la interacción, entre ellos, el tiempo de habla de las partes, y el número de sus intervenciones.

2. Lógico-argumentativo, que indaga: (i) si, desde un inicio y de cara a la audiencia, el entrevistador define con claridad el tema y/o propósito materia de la entrevista; (ii) si, en el preguntar, el entrevistador inquiere por temas sin relevancia política y/o sin coherencia lógica con el desarrollo de la interacción; y, (iii) si, a lo largo del desarrollo de la entrevista, el entrevistador interrumpe la elaboración de las ideas del entrevistado y/o no le permite un desarrollo argumentativo coherente.

3. De pertinencia informativa, que indaga: (i) si se evidencia falta de preparación del entrevistador en el manejo de la información a lo largo del desarrollo de la entrevista, así como en la elaboración de las preguntas que hace al entrevistado; (ii) el tipo de evidencia y/o fuente de información sobre la que se sustentan las intervenciones del entrevistador (lo que permitirá identificar la pertinencia y/o confiabilidad de la misma); y, (iii) el tratamiento que el entrevistador brinda a la evidencia y/o fuente de información sobre la que se soporta el entrevistado.

4. De interacción y comunicación, que indaga: (i) si el entrevistador distorsiona los hechos, personajes y/o mensajes abordados en la entrevista, provengan estos, o no, del entrevistado (caricaturizándolos, recurriendo al habla coloquial, o reformulándolos); (ii) si, el entrevistador interfiere en la entrevista mediante el lenguaje no verbal (gestos, posición corporal, aspiraciones, exhalaciones, tono de voz); (iii) si, el entrevistador realiza actos de habla distintos a las preguntas (afirmaciones, juicios, exigencias).

\section{Hallazgos y conclusiones}

Como hallazgos ${ }^{7}$ encontramos que el caso Todo se sabe difiere, sustancialmente, de la conceptualización de la EPTV realizada desde diversos ámbitos del conocimiento, a la par que se divorcia del despliegue de competencias que son las requeridas para el desarrollo de entrevistas eficaces que cumplan con su función social. Si bien, discursivamente, la entrevistadora asimila sus «prácticas» a la «búsqueda de la verdad», estas distan de la neutralidad y objetividad que le son requeridas, $y$, operando en dirección contraria, interfieren con la esencia misma de la práctica social, la cual es que la noticia sea generada desde la persona entrevistada, a quien, por antonomasia, corresponde el protagonismo de la interacción. Por el contrario, en el programa Todo se sabe, la entrevistadora es quien asume el rol protagónico.

7. Imágenes: programa Word. Transcripciones: sistema de símbolos del análisis de la conversación. 
Desde el factor temporal-cuantitativo, el tiempo abarcado por el habla de la entrevistadora alcanza el $43.99 \%$ de la duración total del habla con una persona entrevistada, a lo que se añade el $14.67 \%$ de la duración total del habla del programa que es dedicado, exclusivamente, a sus monólogos; asimismo, sus intervenciones superan en $18 \%$ las intervenciones de la persona entrevistada.
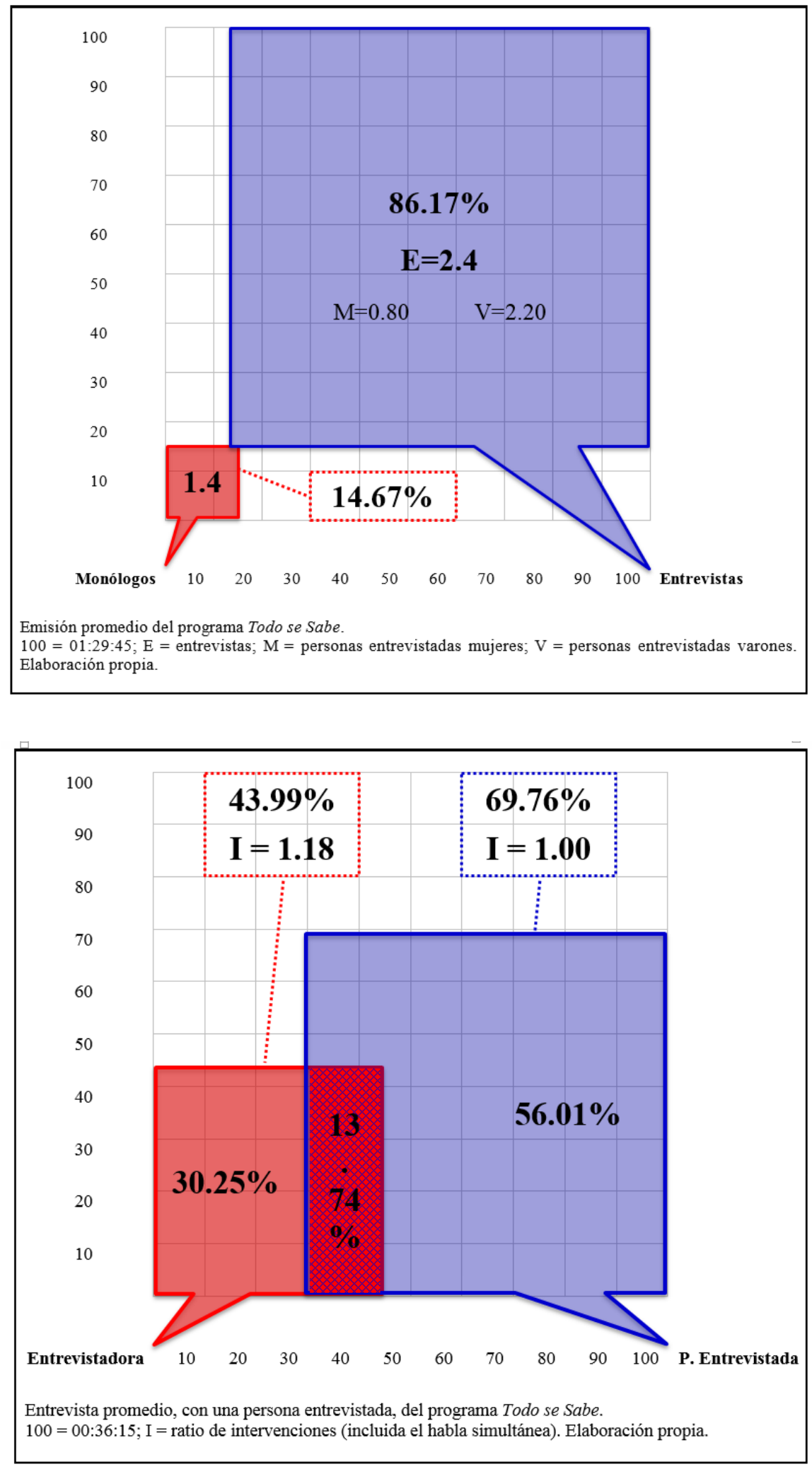
Desde el factor lógico-argumentativo, la entrevista es desarrollada sin un objetivo claro, y en azaroso y contradictorio preguntar;

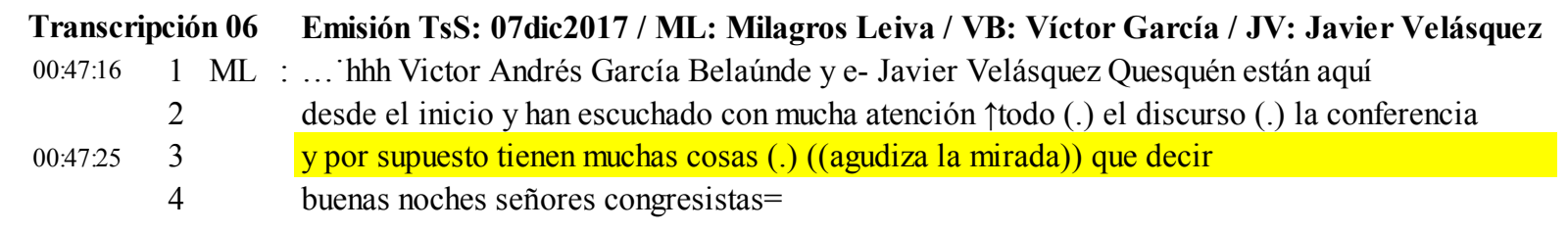

Transcripción 07 Emisión TsS: 04dic2017 / ML: Milagros Leiva / RC: Richard Concepción

\begin{tabular}{|c|c|c|}
\hline & & \\
\hline 00:32:08 & 32 & ML : ....usted duerme tranquilo con su conciencia?... \\
\hline \multirow[t]{4}{*}{ 00:33:05 } & 35 & ML : ...y es po $\uparrow$ sible tomar una decisión tan seria ${ }^{` h h}$ referida a personajes tan poderosos \\
\hline & 36 & en pocas horas?.. \\
\hline & 52 & ML : =usted es un- un Juez perdón por esta expresión porque yo decí- por qué dicen así pero es \\
\hline & 53 & parte del argot e- judicial usted es un juez $h$ verdugo un juez canero (.) como lo conocen?.... \\
\hline \multirow[t]{5}{*}{$00: 37: 25$} & 55 & ML : ...((sobre un caso concreto $))$ porqué para usted eso no es no es $($.$) n- o sea no es suficiente por$ \\
\hline & 56 & qué que yo le entregue mi pasaporte para usted no es señal de que yo no me voy a escapar?... \\
\hline & 76 & ML : usted es farandulero? está altamente p:olitizado como dice el doctar el doctor Otárola?... \\
\hline & 106 & usted votó por Ollanta Humala? ((lo pregunta con rostro adusto)) \\
\hline & 108 & [usted votó] por Toledo? \\
\hline
\end{tabular}

00:51:05 114 ML : ... mj- qué em:: usted siempre:: e::m usted siempre quizo ser Juez doctor?...

mientras que los argumentos de la persona entrevistada devienen en inconclusos y accidentados dadas las constantes intervenciones e interrupciones de la entrevistadora.

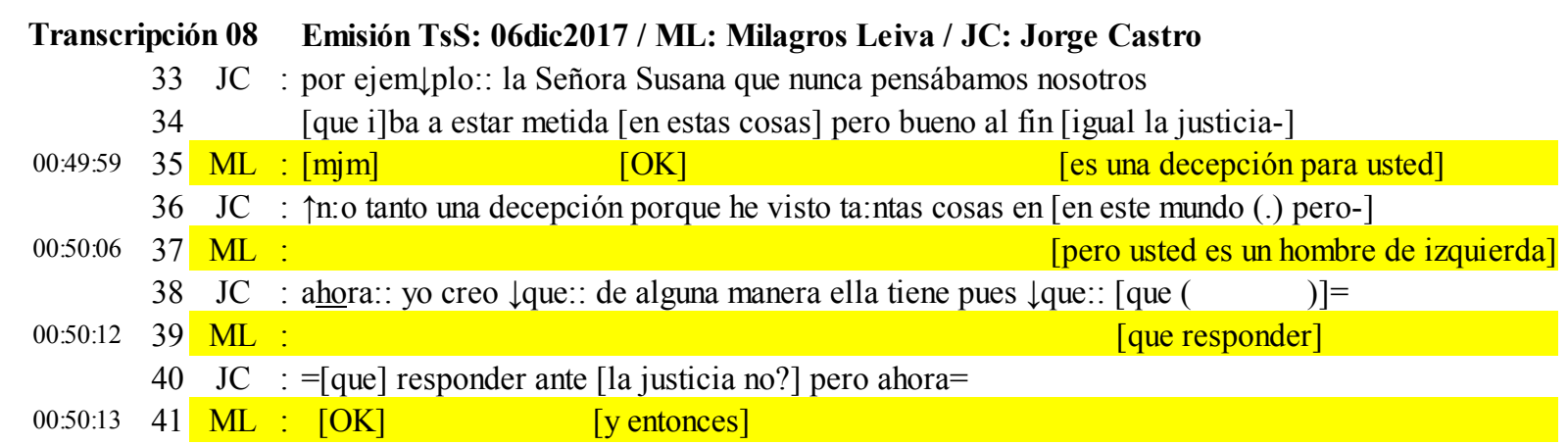

Desde el factor de pertinencia informativa, se evidencia falta de preparación de la entrevistadora, con ausencias notables de investigación y verificación;

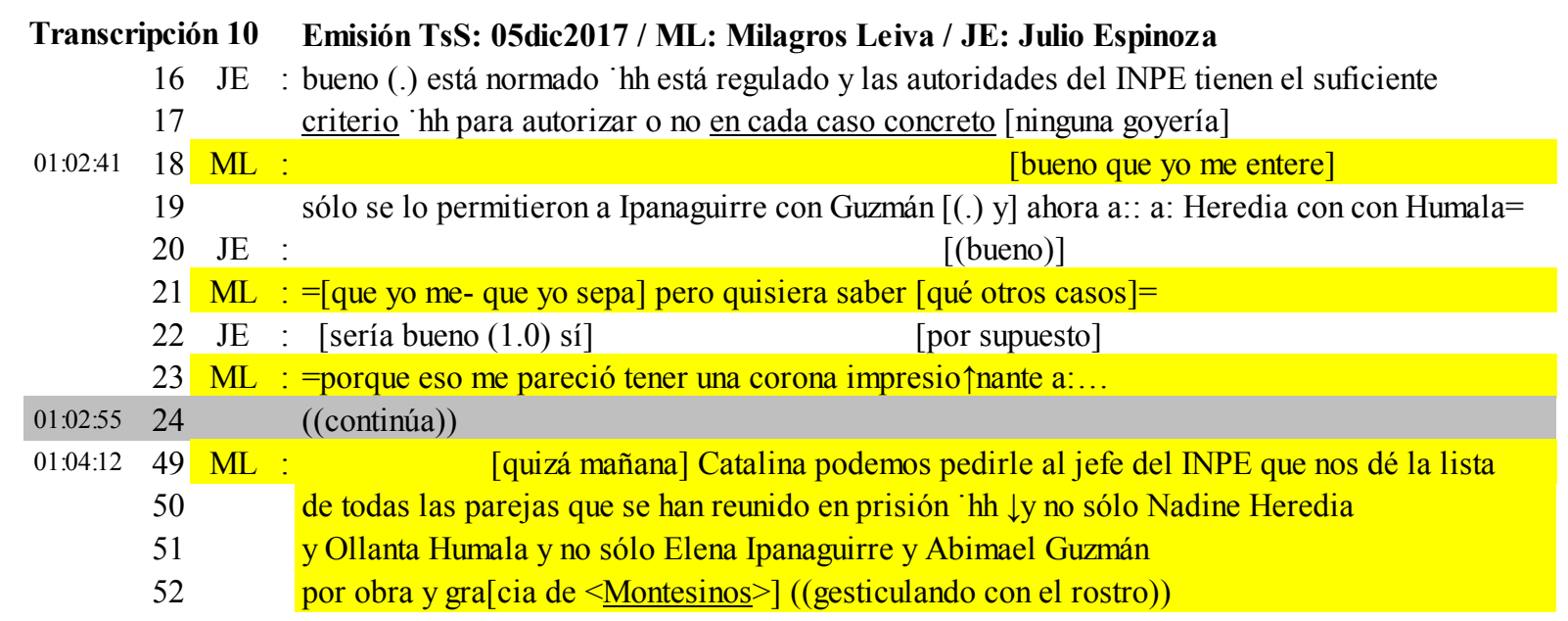


las fuentes de información de la persona entrevistada, y ella misma como fuente de información, son desvirtuadas por la entrevistadora, quien sobrepone sus «fuentes de información», entre ellas, sus meras especulaciones, para reconfirmar, una y otra vez, su propia visión del mundo.

\section{Transcripción 10 Emisión TsS: 05dic2017 / ML: Milagros Leiva / JE: Julio Espinoza}

01:05:07 60 ML : ....ay no::: no ^sea tan inoce::nte pues doctor s- Julio César Espinoza usted es bien bueno

61 a mí me cae bien usted ((gestilando con el rostro)) 'hh porque en el fondo claro me trata-

62 nos trata de convencer a los que no tien- de repente a los que no tienen memoria no?

\section{Transcripción 10 Emisión TsS: 05dic2017 / ML: Milagros Leiva / JE: Julio Espinoza}

01:03:09 25 ML : ... a: el doctor Pedraza de repente ‘hh A:: pero también pues el doctor Pedraza ha sido

26 jefe del INPE por ahí también puede haber pesado no?

27 JE : bueno (.) habría que: ya:: entrar a un:: marco de especula[ciones no?]=

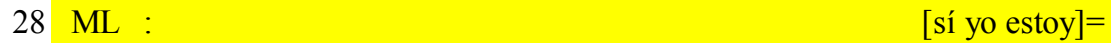

29 JE : =[pero la especulación como comprenderás]=

30 ML : =[entrando como periodista tengo que entrar en la especulación]=

\section{Transcripción 17 Emisión TsS: 08dic2017 / ML: Milagros Leiva / GL: Germán Leguía /}

\section{FC: Felipe Cantuarias}

00:50:25 1 ML : ...y también ha venido Felipe Cantuarias que es miembro de la Comisión de Gobernanza

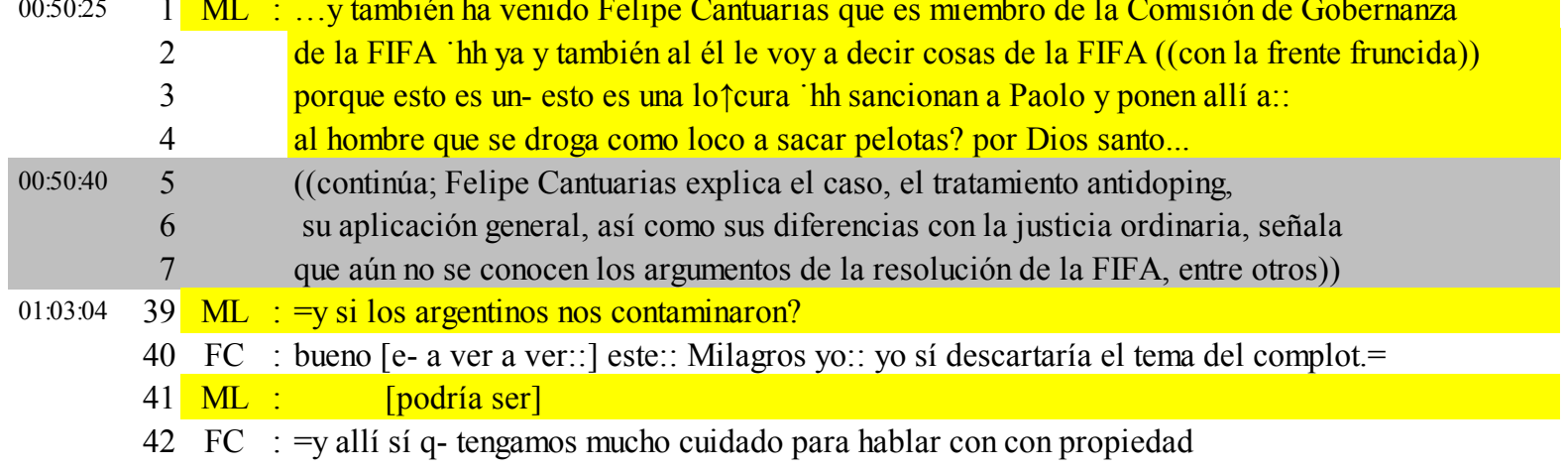

Desde el factor de interacción y comunicación, a través de diversos mecanismos, la entrevistadora distorsiona hechos, personajes y/o mensajes;

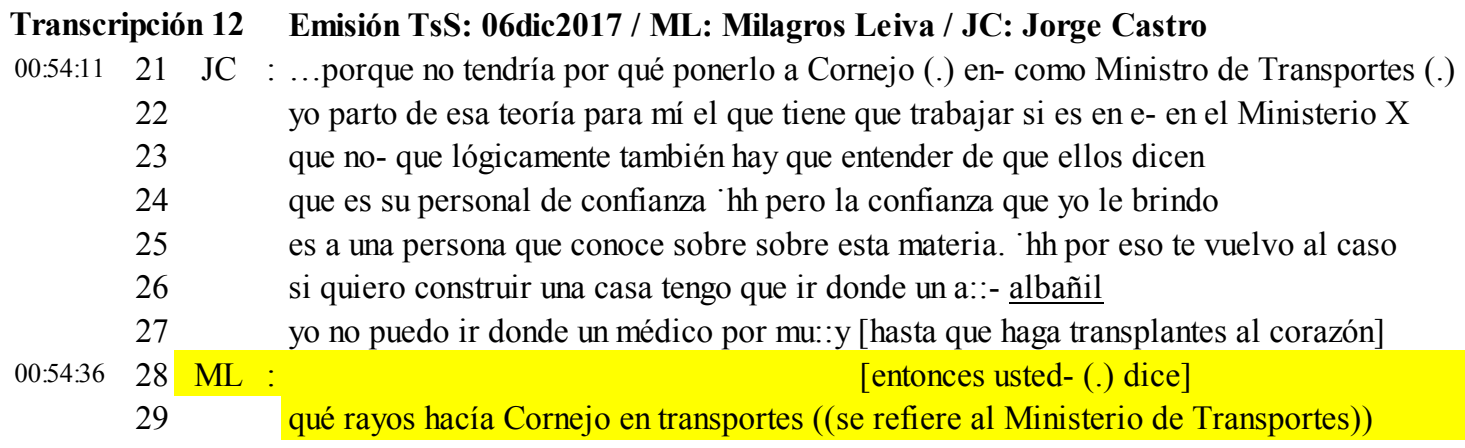


interfiere en el desarrollo de la entrevista con su lenguaje no verbal;

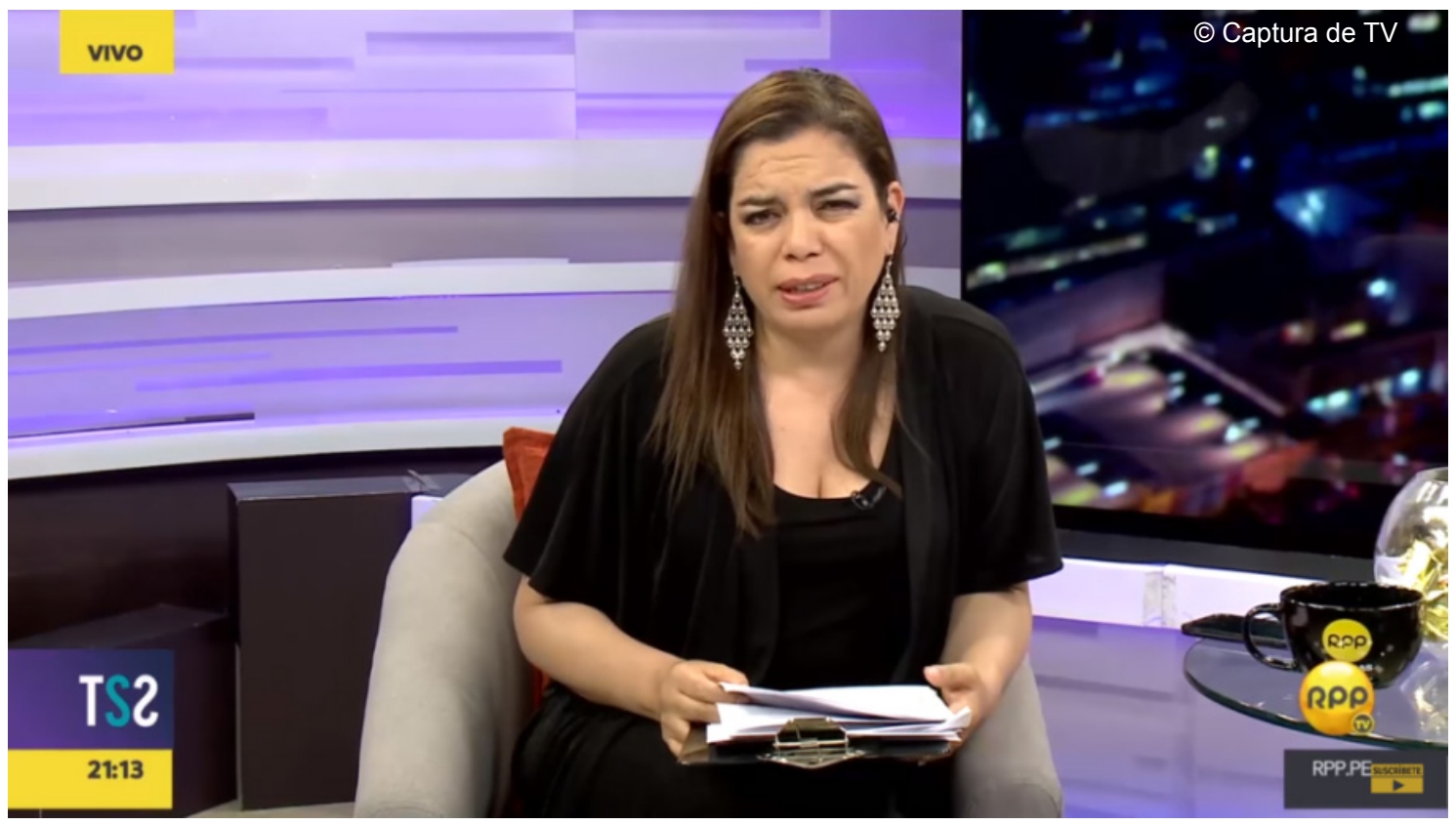

Gesto con el que emite las líneas 3 y 4 de la Transcripción 04.

\section{Transcripción 04 Emisión TsS: 04dic2017 / ML: Milagros Leiva / GS: Gregorio Santos}

00:06:38 1 ML : bueno por lo pronto ya sé que al Juez Richard Concepción Carhuancho no le ha pasado na $\downarrow$ da.

2 sólo que se ha retrasado así que 'hh vamos a iniciar de inmediato con Gregorio Santos (1.0)

00:06:49 3 em:::: ((hace un sonido con la boca)) (.) que bueno imagino que

4 va a ser candidato a la presi $\uparrow$ dencia no lo sé ((gesticulando con la frente fruncida)) (.)

5 en río revuelto ganancia de pescadores (.) cómo está señor Santos?

6 GS : (.) buenas no[ches]

así como, abierta y expresamente, manifiesta actos de habla distintos a las preguntas: opina, afirma, niega, adjetiva, exige, juzga.

Transcripción 02 Emisión TsS: 29ago2017 / ML: Milagros Leiva / JZ: José Zúñiga / AD: Ángel Díaz

13 ML : me imagino que::: que::: bueno usted ha sido separado.

$14 \mathrm{JZ}$ : (1.0) sí tengo entendido que [nos han separado]

00:36:01 15 ML : $\quad$ [yo ayer pedí que lo] botaran.

\section{Transcripción 03 Emisión TsS: 23oct2017 / ML: Milagros Leiva}

00:04:35 16 ML : ‘hh y disculpen. el presidente del INEI este el señor Aníbal Sánchez que estuvo el e::1

17 viernes pasado en este programa y que es una persona 'hh que $\uparrow$ no?

18 que tiene sentido del humo::r que es ama $\uparrow b l e(1.0)$ lo que ha demostrado ahora es

19 una empatía CERO. (1.0) porque él en lugar de salir (.) y ofrecerle discu::lpas a la víctima

00:04:55 20 de pedirle PERDÓN DE RODILLAS POR NO HABERLA PROTEGIDO

21 por no haber puesto resguardo a las mujeres que fueron a empadronar (.) qué ha $\uparrow$ hecho?

22 se ha metido debajo de su cama y no habla. (1.0) y entonces $\uparrow$ claro (.) la la e- q((continúa el monólogo))

00:06:29 $41 \quad$ hh entonces Aníbal Sánchez YA DEBERÍA ESTAR EN SU CASA

42 AVERGONZADO RENUNCIADO 'hhh y él debería haberle dicho al presidente

43 FRACASÉ (.) han violado a una mujer (.) han golpeado a otra (.) a la- a otra la han acosado (.)

00:06:42 $44 \quad$ señor presidente me vo:y 'h soy un fracaso (1.0) PERO NO (.) A NADIE LE IMPORTA (.)

45 ni si quiera al presidente Kuczynski (.) si siquiera Kuczynski ha salido a decir PIDO PERDÓN

46 QUÉHH ES EHHSTO? (.) o sea por Diohhs qué quieren? no. 'hh pero de repente si moría 
Transcripción 07

00:30:33 19 ML

20

21

22

23

24

25

26

27
Emisión TsS: 04dic2017 / ML: Milagros Leiva / RC: Richard Concepción

.. hh para mí usted es el hombre del año. es el hombre que ha hecho noticia

e- pese a muchas presiones políticas empresariales mediáticas ' $h$ h (.) de uno y otro lado usted se ha mantenido en sus trece (.) 'hh ha decidido lo que cree conveniente (.) ((sonido con la boca)) y:: hoy día ha dicho muy tempra:no: en RPP que usted no se deja llevar por ningún tipo de presión. 'hh esto es re $\uparrow a l$ ? (.) 'hh juez e: Concepción Carhuancho porque: la presión mediática es fuerte ‘hh la presión política lo es más 'hh y la- p:resión emp:resarial el dinero: ‘hh pesa mucho. cómo ha hecho para mantenerse independiente?...

Ahora bien, ¿cómo política, poder y democracia se encarnan en el caso estudiado? Que la EPTV se encuentra atravesada por la política va más allá de «lo evidente» (esto es, que la EPTV tiene como entrevistados a actores políticos y como materia de discusión, acontecimientos políticos):

La EPTV produce noticia política. Bajo pretensión noticiosa, entrevistadora y persona entrevistada se embarcan en una interacción que tiene como objeto decir cómo es o debería ser el mundo, lo que solía tener como principal fuente de información a la persona entrevistada, pero que, con la reconfiguración identificada, es la entrevistadora quien adquiere el rol protagónico en ese decir.

Lo noticioso surge del proceso de producción del discurso, el cual discurre por el camino que traza la entrevistadora, quien es responsable de las preguntas que encausan la información recibida como respuesta.

El discurso que se produce es en sí una práctica política (sostiene y cambia relaciones de poder) y una práctica ideológica (constituye, sostiene y cambia significaciones del mundo) (Fairclough, 1992, p. 67).

Por su parte, poder es «la capacidad de A para motivar a B a pensar o hacer algo que B, de otra manera, no hubiera pensado o hecho», siendo que «tener y ejercer poder significa ser capaz — en grados diferentes - de influenciar, usar, determinar, ocupar, o incluso cerrar el espacio de las razones de otros» (Forst, 2014, pp. 5-7).

A la luz de estos conceptos, identificamos a una entrevistadora que, contra su rol de hacer preguntas, plantea abiertamente su visión del mundo, percepciones, opiniones y exigencias, las que emite sin seguir rigurosos procesos de investigación y/o verificación. Asimismo, sin reparo: distorsiona hechos, eventos y personajes; desacredita las fuentes de información de la persona entrevistada, y a ésta misma en su calidad de fuente de información (contrariamente a la razón de ser de la EPTV), y en su lugar, sobrepone sus propias «fuentes de información» (entre ellas, sus meras especulaciones), cerrando así el espacio de las razones en perjuicio de la audiencia, a quien no llegan, de forma clara, las razones de la persona entrevistada (por efecto de la interferencia de la entrevistadora). 
Ello tiene un doble efecto: (i) las trabas que enfrentan las personas entrevistadas para una adecuada elaboración de sus razones hacen que éstas no sean puestas a prueba en sus propios términos (sino en los términos distorsionados producto de la intervención de la entrevistadora); (ii) las razones de la entrevistadora - de permanente presencia en un programa de emisión diaria, en hora punta, y con monólogos emitidos sin interferencia alguna - tienen mayor capacidad de influenciar, usar, determinar y ocupar el espacio de las razones de la audiencia, en sentidos que solo reconfirman, una y otra vez, la visión del mundo de aquella visión ya adoptada antes del desarrollo de la entrevista, siendo que la información que se desprende de ésta no le produce mella alguna. En buena cuenta, la entrevistadora hace política y ejerce poder.

Finalmente, si bien hay quien podría alegar que determinar qué constituye una buena o mala entrevista radica en una apreciación subjetiva, la tesis se ha enfocado en los requerimientos mínimos para que la EPTV cumpla con las exigencias y garantías de un Estado democrático. El caso Todo se sabe - como manifestación de un fenómeno que se viene generalizando en la televisión peruana- no los cumple: su entrevistadora hace política y ejerce poder. Frente a ello, no existe instancia de rendición de cuentas para este tipo de actores políticos que claman para sí las garantías de libertad de expresión y diversidad de fuentes de información que, a través de sus propias «prácticas», a otros niegan, deviniendo en instancias de dedemocratización ${ }^{8}$ micro-sociológicas (quizá por ello, imperceptibles), que dan paso a discursos que crean una realidad política que clama por un cambio urgente.

\section{Referencias bibliográficas}

Clayman, S., \& Heritage, J. (2004). The news interview. Journalists and public figures on the air (Segunda ed). Cambridge: Cambridge University Press.

Dahl, R. (1989). Democratización y oposición pública. In La poliarquía: participación y oposición (pp. 13-25). Madrid: Tecnos.

Del Río Villanueva, C. (2018). Política, poder y democracia en el proceso de producción del discurso de la entrevista política de televisión en vivo: El caso Todo se Sabe (tesis de maestría). Pontificia Universidad Católica del Perú. Retrieved from http://tesis. pucp.edu.pe/repositorio/handle/123456789/13209

Fairclough, N. (1992). Discourse and Social Change. London: Polity Press.

Forst, R. (2014). Justification and critique. Towards a critical theory of politics. Cambridge: Polity Press.

Tilly, C. (2007). Democracy. Cambridge: Cambridge University Press.

8. Concepto inspirado por Tilly (2007). 